\title{
The histone deacetylase inhibitor, Trichostatin A, induces G2/M phase arrest and apoptosis in YD-10B oral squamous carcinoma cells
}

\author{
TRINH DUC ANH ${ }^{1}$, MEE-YOUNG AHN ${ }^{1}$, SOO-A KIM ${ }^{2}$, JUNG-HOON YOON ${ }^{1}$ and SANG-GUN AHN ${ }^{1}$ \\ ${ }^{1}$ Department of Pathology, Chosun University College of Dentistry, Gwangju 501-759; ${ }^{2}$ Department of Biochemistry, \\ Dongguk University College of Oriental Medicine, Gyeongju 780-714, Republic of Korea
}

Received August 4, 2011; Accepted September 16, 2011

DOI: $10.3892 /$ or.2011.1496

\begin{abstract}
Histone acetylation is one of the key chromatin modifications that control gene transcription during development and tumorigenesis. Recently, it was reported that the histone deacetylase inhibitor, Trichostatin A (TSA), induces growth arrest and apoptosis in tumors. However, the molecular mechanisms responsible for its antitumor effects are not clear. The purpose of this study was to investigate the effect of TSA on human oral squamous carcinoma cells and to determine the mechanisms underlying the antitumor activity of TSA. MTT assays showed that TSA inhibited cell proliferation in YD-10B cells. TSA also effectively arrested cell cycle progression at the $\mathrm{G} 2 / \mathrm{M}$ phase through the up-regulation of $\mathrm{p} 21^{\mathrm{waf}}$ expression, down-regulation of Cyclin B1 and reduction of the inhibitory phophorylation of $\mathrm{Cdc} 2$. In addition, mitochondrial membrane destruction was induced by a $48 \mathrm{~h}$ TSA treatment. TSA also induced cytochrome $\mathrm{c}$ release and proteolytic activation of caspase 3 and caspase 7 in YD-10B cells. Taken together, these observations in YD-10B oral cancer cells reveal the potential value of TSA in inhibiting oral tumor growth.
\end{abstract}

\section{Introduction}

Histone deacetylases (HDACs) which induce hydrolysis of the $\varepsilon$-amino acetyl moiety on specific acetylated lysine residues

Correspondence to: Dr Sang-Gun Ahn or Dr Jung-Hoon Yoon, Department of Pathology, Chosun University School of Dentistry, 375 Seosuk-Dong, Dong-gu, Gwangju 501-759, Republic of Korea

E-mail: ahnsg@chosun.ac.kr

E-mail: jhyoon@chosun.ac.kr

Abbreviations: HDACs, histone deacetylases; HDIs, histone deacetylase inhibitors; TSA, Trichostatin A; Cdk2, cyclin-dependent kinase 2; Plk1, polo-like kinase 1; PARP, poly(ADP-ribose) polymerase; Ac-H3, acetylation of histone H3; Bcl-2, B-cell lymphoma 2; Bax, Bcl-2-associated $\mathrm{X}$ protein

Key words: histone deacetylases, Trichostatin A, cell cycle, apoptosis, oral cancer within core histones, are known to repress transcription by associating with gene promoters (1). A number of findings suggest that the transcriptional repression of tumor-suppressor genes by the overexpression and aberrant recruitment of HDACs to their promoter region could be a common phenomenon in tumor onset and progression (2). On the contrary, histone deacetylase inhibitors (HDIs) induce the accumulation of acetylated histones, resulting in the relaxation of chromatin structure and greater accessibility to the transcriptional machinery. HDIs elicit multiple biological effects based on how they alter the acetylation patterns of histones and non-histone proteins (3-5).

TSA, one of the most common HDIs with a hydroxamic acidic group, is a potent inhibitor of HDACs (6). Recently, TSA has been reported to have inhibitory effects on cell proliferation, cell migration and to induce apoptosis in various cancer cell lines (7-12). One of the most notable effects of TSA on transformed cells is its ability to halt cell cycle transition. The combined increase of cyclin-dependent kinase (Cdk) inhibitors, such as $\mathrm{p} 21^{\mathrm{waf}}$ and the decrease of cyclins in response to TSA activity may account for the reduced Cdk activity and may cause cell cycle arrest. TSA-induced p $21^{\text {waf }}$ expression is independent of p53 and correlates with the altered expression of proteins associated with the $\mathrm{p} 21^{\mathrm{waf}}$ promoter, including an increase in the acetylation of histones $(13,14)$. It has been reported that TSA induces apoptosis through the mitochondrial pathway by elevating Bax protein levels, causing the release of cytochrome $\mathrm{c}$ from mitochondria and activating the caspase cascade. Additionally, the overexpression of either Bcl-2 or Bcl-XL, which protect mitochondria, inhibit TSA-induced apoptosis (12). Alternatively, TSA has been demonstrated to trigger caspase-independent apoptosis in human gastric cancer cells and non-small cell lung carcinoma cells $(15,16)$.

In general, the underlying mechanisms of TSA in oral cancer have not been fully elucidated. In this study, we examined the effects of TSA on cell proliferation, cell cycle progression and cell death in YD-10B cells. We found that TSA induced the accumulation of acetylated histones in YD-10B cells, leading to the suppression of proliferation and the induction of apoptosis. This evidence provides a molecular basis for the treatment of oral cancer patients with this pharmacological agent. 


\section{Materials and methods}

Reagents and antibodies. Trichostatin A (TSA) was purchased from Sigma Chemical Co. (St. Louis, MO). Antibodies directed against Bax, Bcl-2, pro-caspase 3, pro-caspase 7, actin, Plk1 and Cyclin B1 were purchased from Santa Cruz Biotechnology (Santa Cruz, CA). Antibodies directed against PARP, cleaved caspase 3, cleaved caspase 7, cleaved caspase 9, p21 ${ }^{\text {waf }}$, cytochrome $\mathrm{C}$, acetylated histone $\mathrm{H} 3, \mathrm{p}-\mathrm{Cdc} 2$ and $\mathrm{p}-\mathrm{Cdc} 25 \mathrm{c}$ were supplied by Cell Signaling Technology (Beverly, MA).

Cell culture. YD-10B oral squamous carcinoma cells were purchased from the Korean Cell Line Bank. These cells were cultured in RPMI-1640 medium (Gibco-BRL) with $10 \%$ FBS (Gibco-BRL), $100 \mathrm{U} / \mathrm{ml}$ penicillin and $100 \mu \mathrm{g} / \mathrm{ml}$ streptomycin (Invitrogen, Carlsbad, CA) in humid air with $5 \% \mathrm{CO}_{2}$ at $37^{\circ} \mathrm{C}$.

MTT assay. YD-10B cells ( $1 \times 10^{5}$ per well) were seeded into 12-well plates. After drug treatment, 3-(4,5-dimethylthiazol2-yl)-2,5-diphenyl-tetrazolium bromide (MTT) solution $(5 \mathrm{mg} / \mathrm{ml}$ in PBS) was added and cells were incubated at $37^{\circ} \mathrm{C}$ for $3 \mathrm{~h}$. The culture medium was subsequently aspirated and acid isopropanol $[0.04 \mathrm{~mol} / \mathrm{l}$ hydrogen chloride $(\mathrm{HCl})$ in isopropanol] was added to dissolve the dark blue crystals. The optical density value of the dissolved solute was then measured using a Microplate Autoreader (Bio-Tek Instruments Inc., Winooski, VT) at a wavelength of $570 \mathrm{~nm}$.

Histone deacetylase activity and Cdc2/Cyclin B kinase activity assays. YD-10B cells were treated with the indicated concentrations of TSA for $48 \mathrm{~h}$. Next, cells were harvested, and whole cell protein was extracted using RIPA lysis buffer. Protein concentrations were identified by a BCA kit. Histone deacetylase activity was measured using the SensoLyte ${ }^{\circledR} 520$ HDAC Activity Assay kit (AnaSpec, Inc.) and Cdc2/Cyclin B kinase activity was assessed using CycLex Cdc2-Cyclin B Kinase Assay kit (Biotium, Inc., Hayward, CA). Experimental procedures were performed according to the manufacturer's instructions.

Cell cycle analysis. After TSA treatment, cells were harvested by trypsinization, washed once in ice-cold 1 X PBS, centrifuged at $300 \mathrm{x} \mathrm{g}$ and the resulting cell pellets were fixed in $75 \%$ ethanol. Fixed cells were subsequently stained with $250 \mu \mathrm{l}$ of propidium iodide (PI) solution $(20 \mu \mathrm{g} / \mathrm{ml} \mathrm{PI}, 200 \mu \mathrm{g} / \mathrm{ml}$ DNasefree RNase A in $1 \mathrm{X}$ PBS) for $30 \mathrm{~min}$ at $37^{\circ} \mathrm{C}$. DNA content was analyzed usinga Cell LabQuanta SC Flow Cytometer (Beckman Coulter) with an excitation wavelength of $488 \mathrm{~nm}$.

Western blot analysis. YD-10B cells were treated with TSA for $48 \mathrm{~h}$, washed with PBS and harvested in lysis buffer. Samples containing equal amounts of protein were loaded into each lane of a SDS-polyacrylamide gel for electrophoresis and were subsequently transferred onto a polyvinylidene difluoride (PVDF) membrane. After blocking, membranes were incubated with the indicated antibody.

DAPI staining. Cells were seeded onto glass coverslips in 24-well plates. Forty-eight hours after TSA treatment, cells were stained with $1 \mu \mathrm{g} / \mathrm{ml}$ DAPI for $10 \mathrm{~min}$ at room temperature. Later, the coverslips containing cells were mounted onto microscope slides using mounting solution and were analyzed by fluorescence microscopy.

Mitochondrial membrane potential determination. YD-10B cells were cultured on glass coverslips in 6-well plates and were treated with different doses of TSA for $48 \mathrm{~h}$. The mitochondrial membrane potential was detected using JC-1 mitochondrial membrane potential detection kit from Biotium, Inc. Pictures were captured using an Olympus IX71 fluorescent microscope.

Flow cytometry assay for apoptosis. YD-10B cells $\left(1 \times 10^{4} / \mathrm{ml}\right)$ were treated with various concentration of TSA for $48 \mathrm{~h}$. Next, cells were harvested with trypsin, stained with both Annexin V-FITC and PI according to the manufacturer's protocol (Invitrogen) and were analyzed using the Cell Lab Quanta SC flow cytometer (Beckman Coulter).

Statistical analysis. The data obtained from the different groups are expressed as mean \pm SD. All statistical calculations were carried out using Microsoft Excel. Values of $\mathrm{P}<0.05$ were considered to indicate significant differences.

\section{Results}

Effect of TSA on YD-10B cell proliferation. To explore the effects of TSA on cell proliferation in oral squamous carcinoma cells, YD-10B cells were treated with TSA at various concentrations $(0.05-5 \mu \mathrm{M})$ for 24 and $48 \mathrm{~h}$ and proliferation was measured using MTT assay. Treatment with TSA inhibited the proliferation of YD-10B cells in a dose- and time-dependent manner (Fig. 1A). Changes in cell morphology showed numerous dead and floating cells following treatment with either 1 or $2 \mu \mathrm{M}$ of TSA for $48 \mathrm{~h}$ (Fig. 1B). These results indicate that TSA induces anti-growth and/or cell-killing effects in YD-10B cells.

Effect of TSA on HDAC activity in YD-10B cells. We next examined whether HDAC activity is important for the antiproliferative effect of TSA in YD-10B cells. Following incubation with the indicated concentrations of TSA for $48 \mathrm{~h}$, HDAC activity assays were performed on whole cell extracts. TSA strongly inhibited HDAC activity in a dose-dependent manner (Fig. 2A). Furthermore, Western blot analysis revealed that TSA dramatically enhanced the acetylation of histone $\mathrm{H} 3$ in YD-10B cells after treatment with 1 or $2 \mu \mathrm{M}$ TSA (Fig. 2B). These results suggest that modifying the epigenetic status of chromatin is involved in mediating the effects of TSA in YD-10B cells.

Cell cycle arrest effect of TSA in YD-10B cells. To determine the effects of TSA on the cell cycle, YD-10B cells were treated with TSA for $48 \mathrm{~h}$ and the cell cycle phase distribution was analyzed by flow cytometry. As shown in Fig. 3A and B, TSA treatment resulted in an increased number of cells in the G2/M phase (13.13-40.44\%) with a concomitant reduction of cells in the G1 phase (79.39-27.94\%). These data indicate that TSA effectively induces cell cycle arrest at the $\mathrm{G} 2 / \mathrm{M}$ phase in YD-10B cells. 
A

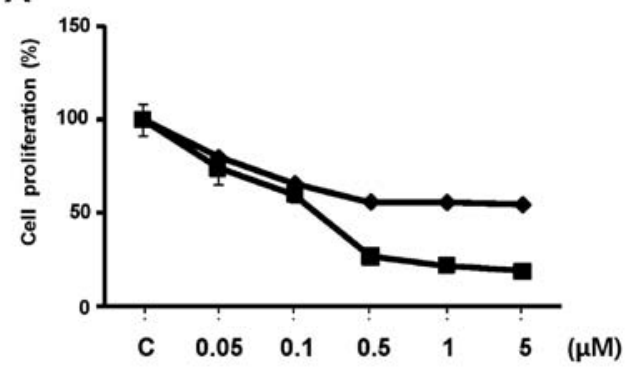

B

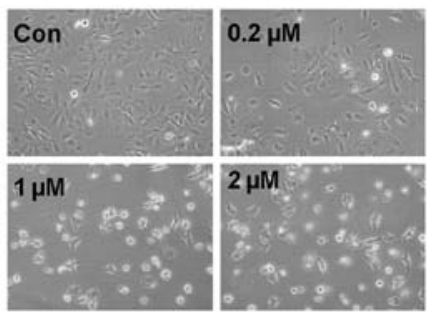

Figure 1. Effect of TSA on cell proliferation. YD-10B cells were treated with TSA for 24 or $48 \mathrm{~h}$. (A) Cell proliferation was analyzed by the MTT assay ( $\bullet, 24 \mathrm{~h}$; I, $48 \mathrm{~h}$ ). (B) Morphological changes in YD-10B cells after TSA treatment for $48 \mathrm{~h}(0,0.2,1.0$ or $2.0 \mu \mathrm{M})$. Pictures were taken with a phase contrast microscope at x100 magnification.

A

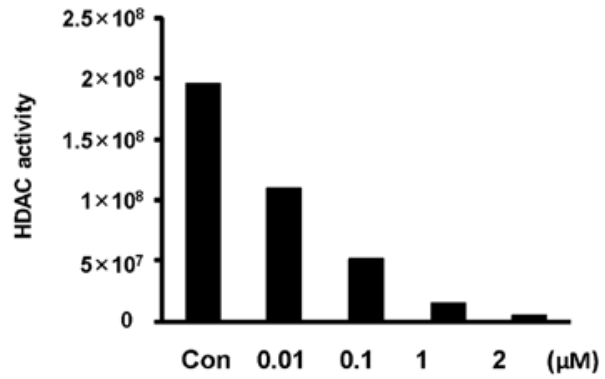

B TSA

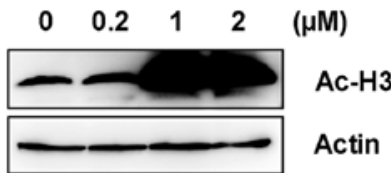

Figure 2. The inhibitory effect of TSA on HDAC activity. YD-10B cells were treated with TSA for $48 \mathrm{~h}$. (A) The whole-cell extract was subsequently used for an HDAC activity assay or (B) Western blot analysis to detect the acetylation of histone H3 (Ac-H3).

A

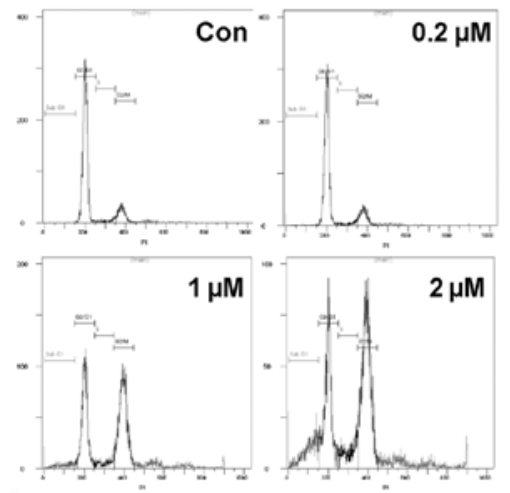

C

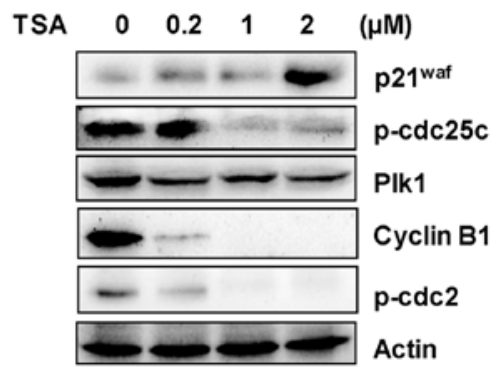

B

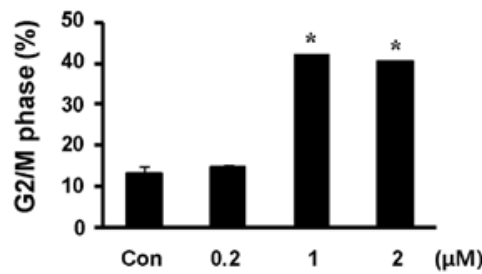

D

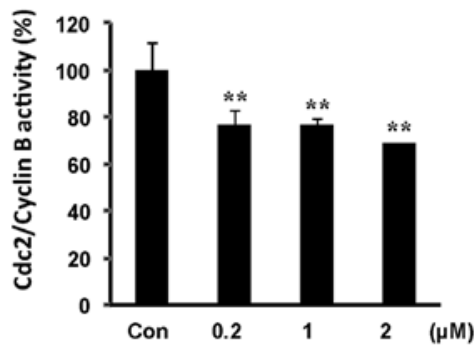

Figure 3. Effect of TSA on cell cycle progression. YD-10B cells were treated with the indicated doses of TSA for $48 \mathrm{~h}$. After fixation with $70 \%$ ethanol, cells were stained with PI and analyzed by FACS. (A) Changes in cell phase distribution between various concentrations of TSA. (B) Proportion of cells in G2/M phase. Error bars indicate \pm SD values. ${ }^{*} \mathrm{P}<0.001$ compared to control. (C) YD-10B cells were treated with TSA for $48 \mathrm{~h}$, after which whole cell protein was extracted, and the expression of G2/M-related proteins was analyzed by Western blotting. (D) Whole-cell protein was used to examine the activity of the Cdc2/Cyclin B complex. ${ }^{* * *} \mathrm{P}<0.01$ compared to control. 
A
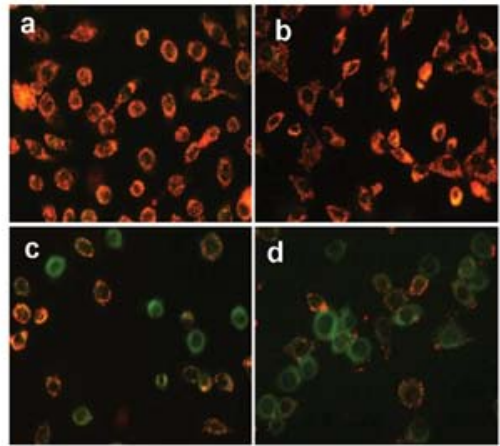

d

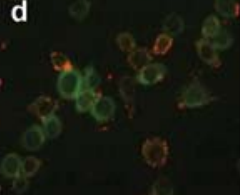

B
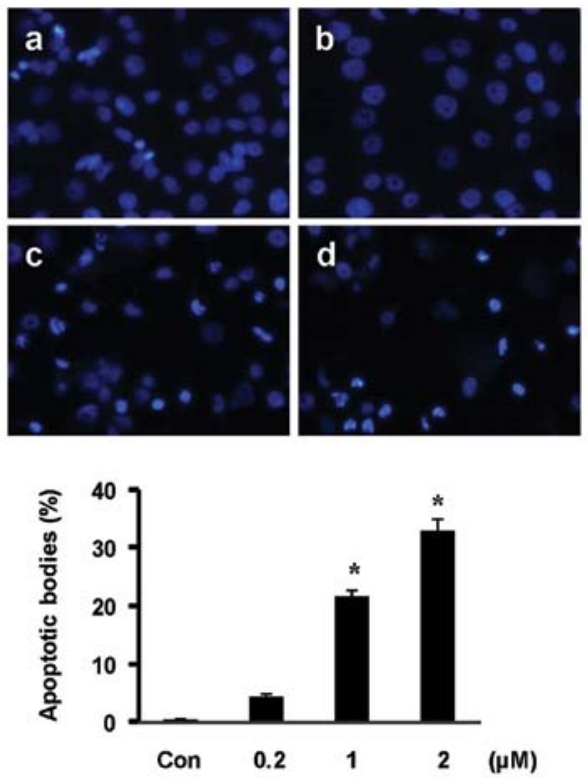

Figure 4. Effect of TSA on the mitochondrial membrane potential and cell death. (A) YD-10B cells were treated with TSA for $48 \mathrm{~h}$ prior to analysis using the JC-1 mitochondrial potential detection kit. (B) Cells were incubated with TSA for $48 \mathrm{~h}$ before fixation with ethanol and DAPI staining. The lower panel indicates the percentage of apoptotic cells. Pictures were taken by fluorescence microscopy ( $\mathrm{a}, \mathrm{b}, \mathrm{c}$ and $\mathrm{d}$ represent concentrations of $0,0.2,1.0$ and $2.0 \mu \mathrm{M}$ of TSA, respectively).

We next examined the expression cell cycle proteins that regulate $\mathrm{G} 2 / \mathrm{M}$ in TSA-treated YD-10B cells. Western blot analysis showed that TSA enhanced $\mathrm{p} 21^{\text {waf }}$ expression and inhibited Cyclin B1 and Cdc2 (Fig. 3C). The expression level of p2 $1^{\text {waf }}$ was gradually elevated in cells treated with $2 \mu \mathrm{M}$ TSA, whereas Cyclin B1 expression was inhibited at a concentration of only $0.2 \mu \mathrm{M}$ TSA. In addition, TSA displays an inhibitory effect on the phosphorylation of $\mathrm{Cdc} 25 \mathrm{c}$ and $\mathrm{Cdc} 2$ at doses of 1 or $2 \mu \mathrm{M}$. Plk1, which is one of the most important G2/M cell cycle regulatory proteins, was also inhibited by low-dose TSA treatment (Fig. 3C).

To examine whether TSA affects Cdc2/Cyclin B activity, we performed $\mathrm{Cdc} 2 / \mathrm{Cyclin} \mathrm{B}$ kinase activity assays. The activity of the $\mathrm{Cdc} 2 / \mathrm{Cyclin} \mathrm{B}$ complex was clearly repressed by TSA in a dose-dependent manner (Fig. 3D). Taken together, TSA appears to arrest cell cycle progression at the G2/M phase through regulation of Plk1-modulated Cdc2/Cyclin B complex activity.
Characterization of TSA-induced cell death. To explore the involvement of mitochondria in the cell death inducing the effect of TSA in YD-10B cells, we examined the mitochondrial membrane potential. Cells were incubated with TSA for $48 \mathrm{~h}$ prior to mitochondria staining and fluorescence microscopy was used to observe changes in mitochondrial membrane potential. Control cells, which have high mitochondrial transmembrane potential, displayed red fluorescence in mitochondria, whereas apoptotic or unhealthy cells showed only green fluorescence. Upon treatment with 1 or $2 \mu \mathrm{M}$ of TSA, the mitochondrial membrane was damaged, resulting in alterations to membrane permeability (Fig. 4A). Furthermore, DAPI staining of the nucleus revealed condensation of nuclei, which is indicative of cell death after $48 \mathrm{~h}$ treatment with 1 or $2 \mu \mathrm{M}$ TSA (Fig. 4B).

Next, flow cytometry was used to analyze apoptosis in response to TSA treatment. YD-10B cells were incubated with TSA for $48 \mathrm{~h}$ before dual-staining with Annexin V and PI. TSA induced early and late stage apoptosis, especially at a concentration of $2 \mu \mathrm{M}$, which resulted in an increase of over 20\% compared to control (Fig. 5A). These finding suggest that TSA induces apoptosis in YD-10B cells.

We also examined the expression of apoptosis related proteins in TSA-treated cells. Because cytochrome $\mathrm{c}$ and Bcl-2 family members play an important role in mitochondriadependent apoptosis, we used Western blot analysis to assay the expression of these proteins. Both the expression of Bax and the amount of cytochrome $\mathrm{c}$ detected in the cytosol increased in a dose-dependent manner in response to TSA treatment. Cytochrome $\mathrm{c}$ levels began to increase at a low concentration of TSA $(0.2 \mu \mathrm{M})$. Immunoblot analysis clearly showed a concentration-dependent activation of caspase 3 and caspase 7 , as indicated by the disappearance of a band at $35-\mathrm{kDa}$, which represents pro-caspase 7 . The activation of caspase 7 led to the cleavage of a 119-kDa poly(ADP-ribose) polymerase (PARP) protein to produce an $89-\mathrm{kDa}$ fragment, whereas untreated cells did not show any PARP cleavage (Fig. 5B). These results suggest that TSA induces mitochondria-dependent apoptosis in YD-10B cells.

\section{Discussion}

Oral cancer is one of the fastest growing malignancies, and it is particularly dangerous because of a high risk of producing secondary tumors. There are several types of oral cancers, of which $90 \%$ are classified as squamous cell carcinomas (17). Despite enormous efforts for improvement, survival rates have remained unchanged over 20 years due to a lack of markers for early prognosis and the failure of advanced tumors to respond to chemotherapy (18). In this study, we evaluated the effect of TSA as a therapeutic for oral squamous cell carcinomas.

Recently, growing evidence suggests that the inhibition of HDACs is a promising new strategy in cancer therapy. Various HDAC inhibitors have been shown to exhibit this potent antitumor activity both in vitro and in vivo. Depending on the cell type, HDAC inhibitors have been demonstrated to arrest cells at G0/G1 or G2/M. One such inhibitor, TSA, induced G2/M cell cycle arrest and apoptosis in HeLa and Tca8113 cell lines $(8,13)$. Consistent with these reports, our present study shows 
A

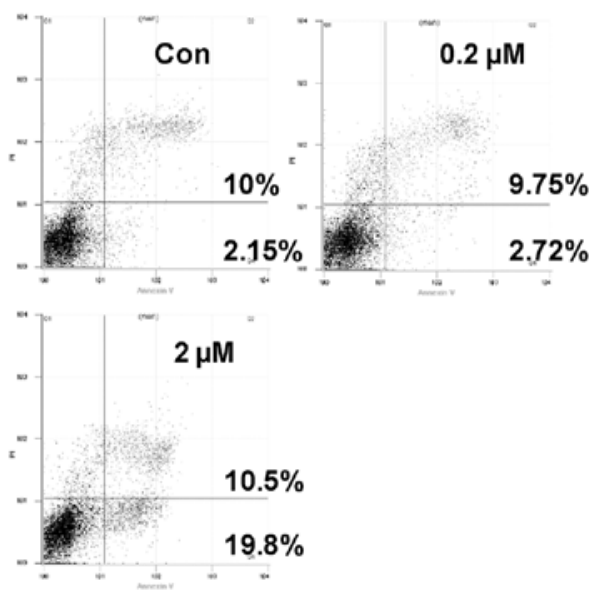

B

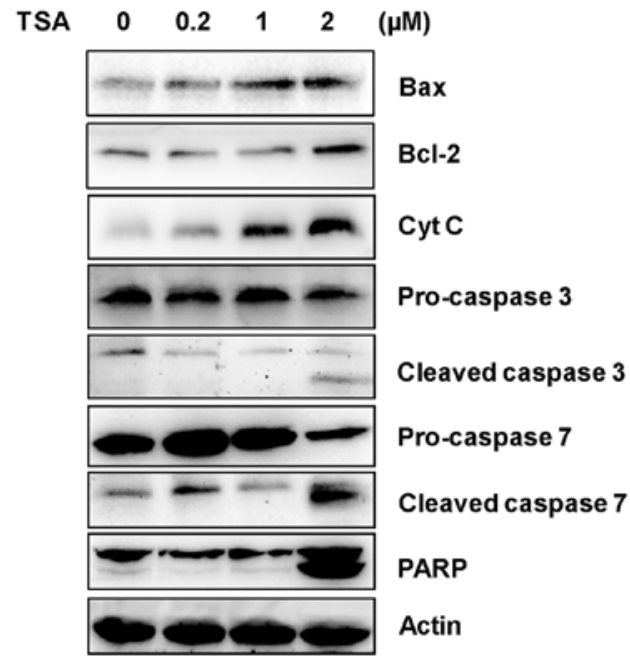

Figure 5. Effects of TSA on apoptosis. (A) YD-10B cells were treated with the indicated doses of TSA for $48 \mathrm{~h}$. Following harvest, cells were stained with both Annexin V and PI and were analyzed by FACS. (B) The whole-cell or cytosolic (for cytochrome c) protein was extracted and the expression of apoptotic proteins was monitored by Western blot analysis.

that TSA induces G2/M cell cycle arrest and apoptosis in YD-10B oral squamous carcinoma cells.

Although TSA exhibits antitumor activity, little is known about its molecular mechanism of action. A recent report showed that TSA enhanced the acetylation of histone $\mathrm{H} 3$ on the p2 $1^{\text {waf }}$ promoter and induced its expression $(8,14)$. In this study, we show that TSA induces the expression of $\mathrm{p} 21^{\text {waf }}$, down-regulates Cyclin B and decreases the inhibitory phosphorylation of Cdc25c. The inhibition of Cyclin B expression and dephosphorylation of Cdc 2 was observed with a low dose $(0.2 \mu \mathrm{M})$ of TSA, but $\mathrm{p} 21^{\text {waf }}$ expression was altered only upon incubation with a high dose of TSA $(2 \mu \mathrm{M})$. Thus, it appears that $\mathrm{p} 21^{\text {waf }}$ is not the unique regulator determining $\mathrm{Cdc} 2 / \mathrm{Cyclin} \mathrm{B}$ complex activity in YD-10B cells. Plk1 has emerged as a potential target of HDACs, due to its wide-ranging effects on G2/M cell cycle regulation. As a kinase, Plk1 alters the phosphorylation status of numerous substrates, including Cyclin B and Cdc25c. Plk1 is responsible for the nuclear translocation of Cyclin B during the onset of the transition from the $\mathrm{G} 2$ phase to mitosis $(19,20)$. Moreover, Plk1 plays an important role in the nuclear import of Cdc25c by way of Ser198 phosphorylation. In turn, Cdc25c directly activates $\mathrm{Cdc} 2$, facilitating the movement of cells through the $\mathrm{G} 2$ checkpoint. In addition to regulating Cyclin B and Cdc25c, Plk1 also promotes the degradation of Wee1 and Myt1 proteins, which are suppressors of $\mathrm{Cdc} 2$, thereby contributing to the activation of the Cdc2/Cyclin B complex $(21,22)$. In this study, Plk1 expression was inhibited by TSA, even at low doses $(0.2 \mu \mathrm{M})$. Therefore, the sensitive response of Plk1 to TSA may account for the decrease we observed in the activation of the phosphorylation of $\mathrm{Cdc} 25 \mathrm{C}$ and of $\mathrm{Cdc} 2$ in response to a low dose of TSA $(0.2 \mu \mathrm{M})$.

HDACs inhibitors promote an open state of chromatin via neutralizing charges in the histone backbone with acetyl groups, which leads to the transcriptional activation of various genes that induce the repression of tumor cell growth and make tumor cells more susceptible to DNA damaging agents (anti-cancer drugs, oxidants, UV) $(5,23)$. In the present study, we found a marked increase in the acetylation of histone $\mathrm{H} 3$ after TSA treatment, suggesting that TSA strongly induces DNA relaxation. Moreover, MTT assays revealed that TSA significantly inhibits the proliferation of YD-10B cells in a dose-dependent manner. Cell morphology and DAPI staining of the nucleus revealed typical characteristics of apoptosis, such as cell shrinkage and condensed DNA, especially at higher doses of TSA.

HDAC inhibitors have been demonstrated to induce apoptosis through both mitochodrial-dependent and death ligand-dependent pathways. Furthermore, the altered expression of several pro-and anti-apoptotic intracellular genes by HDAC inhibitors has been reported (24-26). However, the expression pattern of pro-and anti-apoptotic proteins seems to be cell-type-dependent. For example, TSA decreased the expression of Bcl-2, while expression of the pro-apoptotic factor, Bax, was increased in hepatoma cells (27). In contrast, the expression of Bcl-2 and Bax was unaffected by TSA treatment in glioma cells (28). Therefore, an understanding of the exact mechanisms by which TSA regulates the genes involved in apoptosis is needed in oral squamous cell carcinomas.

We clearly demonstrate that TSA induces apoptosis in YD-10B cells by regulating a series of apoptosis-associated genes, including caspase 3 and caspase 7. We also observed a concentration-dependent increase of Bax levels and the loss of the mitochondrial membrane potential in TSA-treated YD-10B cells. However, TSA did not affect the expression of Bcl-2. In addition, Western blot analysis confirmed an increase in the level of cytochrome $\mathrm{c}$ present in the cytosol. These data suggest that TSA induces cell death through the activation of mitochondria-dependent pathways in YD-10B cells. Although we did not examine caspase 9 activation, we observed cleavage of caspase 7 and caspase 3, which correlated with the decrease of pro-caspase 7 and pro-caspase 3. Additionally, the similar cleaving pattern observed between the caspases and PARP in 
response to TSA treatment suggests that active caspase 7 and caspase 3 are responsible for the proteolytic cleavage of PARP. However, it remains unclear which pathway(s) drive the apoptotic response to TSA. Our data show that cytochrome $\mathrm{c}$ levels were greatly increased, but Bax expression increased only slightly, indicating that the mitochondrial pathway may not be solely responsible for TSA-mediated apoptosis. In fact, TSA has also been reported to stimulate the modulation of death receptors, leading to Fas- or TNF-mediated apoptosis $(12,29)$. Furthermore, TSA was found to induce caspase-independent cell death via the activation of the apoptosis-inducing factor (AIF) pathway in human gastric cancer cells and non-small cell lung carcinoma cells $(15,16)$. Clearly, further studies are required to verify the mechanisms driving apoptotic cell death in YD-10B cells in response to TSA treatment.

Our study provides evidence that the HDAC inhibitor TSA, potently inhibits the proliferation of YD-10B cells in vitro, causing both apoptosis and cell cycle arrest. Thus, TSA is a novel and promising strategy for inhibiting tumor growth in patients with oral cancer.

\section{Acknowledgements}

This research was supported by Basic Science Research Program (20110004555) through the National Research Foundation of Korea (NRF) and the National Research Foundation of Korea (NRF) funded by the Ministry of Education, Science and Technology (No. R13-2008-010-00000-0).

\section{References}

1. Berger SL: The complex language of chromatin regulation during transcription. Nature 447: 407-412, 2007.

2. Ropero $\mathrm{S}$ and Esteller M: The role of histone deacetylases (HDACs) in human cancer. Mol Oncol 1: 19-25, 2007.

3. Shankar S and Srivastava RK: Histone deacetylase inhibitors: mechanisms and clinical significance in cancer: HDAC inhibitorinduced apoptosis. Adv Exp Med Biol 615: 261-298, 2008.

4. Moradei O, Vaisburg A and Martell RE: Histone deacetylase inhibitors in cancer therapy: new compounds and clinical update of benzamide-type agents. Curr Top Med Chem 8: 841-858, 2008.

5. Bolden JE, Peart MJ and Johnstone RW: Anticancer activities of histone deacetylase inhibitors. Nat Rev Drug Discov 5: 769-784, 2006.

6. Marks PA and Xu WS: Histone deacetylase inhibitors: potential in cancer therapy. J Cell Biochem 107: 600-608, 2009.

7. Yoshikawa M, Hishikawa K, Idei M and Fujita T: Trichostatin a prevents TGF-betal-induced apoptosis by inhibiting ERK activation in human renal tubular epithelial cells. Eur J Pharmacol 642: 28-36, 2010.

8. Yao J, Duan L, Fan M and Wu X: NF-kB signaling pathway is involved in growth inhibition, $\mathrm{G} 2 / \mathrm{M}$ arrest and apoptosis induced by Trichostatin A in human tongue carcinoma cells. Pharmacol Res 54: 406-413, 2006.

9. Pan L, Lu J, Wang X, Han L, Zhang Y, Han S and Huang B Histone deacetylase inhibitor trichostatin a potentiates doxorubicin-induced apoptosis by up-regulating PTEN expression. Cancer 109: 1676-1688, 2007.

10. Jang ER, Kim YJ, Myung SC, Kim W and Lee CS: Different effect of protein kinase B/Akt and extracellular signal-regulated kinase inhibition on trichostatin A-induced apoptosis in epithelial ovarian carcinoma cell lines. Mol Cell Biochem 353: 1-11, 2011.
11. Zhou C, Qiu L, Sun Y, Healey S, Wanebo H, Kouttab N, Di W, Yan B and Wan Y: Inhibition of EGFR/PI3K/AKT cell survival pathway promotes TSA's effect on cell death and migration in human ovarian cancer cells. Int J Oncol 29: 269-278, 2006.

12. Kim HR, Kim EJ, Yang SH, Jeong ET, Park C, Lee JH, Youn MJ, So HS and Park R: Trichostatin A induces apoptosis in lung cancer cells via simultaneous activation of the death receptormediated and mitochondrial pathway. Exp Mol Med 38: 616-624, 2006.

13. Noh EJ, Lim DS, Jeong G and Lee JS: An HDAC inhibitor, trichostatin A, induces a delay at G2/M transition, slippage of spindle checkpoint, and cell death in a transcription-dependent manner. Biochem Biophys Res Commun 378: 326-331, 2009.

14. Nishioka C, Ikezoe T, Yang J, Koeffler HP and Yokoyama A: Inhibition of MEK/ERK signaling synergistically potentiates histone deacetylase inhibitor-induced growth arrest, apoptosis and acetylation of histone $\mathrm{H} 3$ on $\mathrm{p} 21^{\text {waf } 1}$ promoter in acute myelogenous leukemia cell. Leukemia 22: 1449-1452, 2008.

15. Wu ZQ, Zhang R, Chao C, Zhang JF and Zhang YQ: Histone deacetylase inhibitor trichostatin A induced caspase-independent apoptosis in human gastric cancer cell. Chin Med J (Engl) 120: 2112-2118, 2007.

16. Hajji N, Wallenborg K, Vlachos P, Nyman U, Hermanson O and Joseph B: Combinatorial action of the HDAC inhibitor trichostatin A and etoposide induces caspase-mediated AIF-dependent apoptotic cell death in non-small cell lung carcinoma cells. Oncogene 27: 3134-3144, 2008.

17. Jemal A, Siegel R, Xu J and Ward E: Cancer statistics, 2010. CA Cancer J Clin 60: 277-300, 2010.

18. Massano J, Regateiro FS, Januário G and Ferreira A: Oral squamous cell carcinoma: review of prognostic and predictive factors. Oral Surg Oral Med Oral Pathol Oral Radiol Endod 102: 67-76, 2006.

19. Glover DM, Hagan IM and Tavares AA: Polo-like kinases: a team that plays throughout mitosis. Genes Dev 12: 3777-3787, 1998

20. Donaldson MM, Tavares AA, Hagan IM, Nigg EA and Glover DM: The mitotic roles of Polo-like kinase. J Cell Sci 114: 2357-2358, 2001

21. Liu XS, Song B and Liu X: The substrates of Plk1, beyond the functions in mitosis. Protein Cell 1: 999-1010, 2010.

22. Lens SM, Voest EE and Medema RH: Shared and separate functions of polo-like kinases and aurora kinases in cancer. Nat Rev Cancer 10: 825-841, 2010.

23. Kim MS, Baek JH, Chakravarty D, Sidransky D and Carrier F: Sensitization to UV-induced apoptosis by the histone deacetylase inhibitor trichostatin A (TSA). Exp Cell Res 306: 94-102, 2005.

24. Acharya MR, Sparreboom A, Venitz J and Figg WD: Rational development of histone deacetylase inhibitors as anticancer agents: a review. Mol Pharmacol 68: 917-932, 2005.

25. Monneret C: Histone deacetylase inhibitors. Eur J Med Chem 40: 1-13, 2005 .

26. Roh MS, Kim CW, Park BS, Kim GC, Jeong JH, Kwon HC, Suh DJ, Cho KH, Yee SB and Yoo YH: Mechanism of histone deacetylase inhibitor trichostatin A induced apoptosis in human osteosarcoma cells. Apoptosis 9: 583-589, 2004.

27. Herold C, Ganslmayer M, Ocker M, Hermann M, Geerts A, Hahn EG and Schuppan D: The histone-deacetylase inhibitor trichostatin A blocks proliferation and triggers apoptotic programs in hepatoma cells. J Hepatol 36: 233-240, 2002.

28. Sawa H, Murakami H,Ohshima Y, Sugino T, Nakajyo T, Kisanuki T, Tamura Y, Satone A, Ide W, Hashimoto I and Kamada H: Histone deacetylase inhibitors such as sodium butyrate and trichostatin A induce apoptosis through an increase of the bcl-2-related protein Bad. Brain Tumor Pathol 18: 109-114, 2001.

29. Shankar S, Singh TR, Fandy TE, Luetrakul T, Ross DD and Srivastava RK: Interactive effects of histone deacetylase inhibitors and TRAIL on apoptosis in human leukemia cells: Involvement of both death receptor and mitochondrial pathways. Int J Mol Med 16: 1125-1138, 2005. 